\title{
Editorial
}

\section{Special Issue: Gold Nanoparticles for Catalytic Applications}

\author{
Sónia A. C. Carabineiro ${ }^{1,2}$ (D) \\ 1 Laboratório de Catálise e Materiais (LCM), Laboratório Associado LSRE-LCM, Faculdade de Engenharia, \\ Universidade do Porto, Rua Dr. Roberto Frias s/n, 4200-465 Porto, Portugal; \\ sonia.carabineiro@tecnico.ulisboa.pt \\ 2 Centro de Química Estrutural, Instituto Superior Técnico, Universidade de Lisboa, Av. Rovisco Pais 1, \\ 1049-001 Lisboa, Portugal
}

Received: 8 July 2019; Accepted: 15 July 2019; Published: 19 July 2019

Keywords: gold; nanoparticles; catalysis; photocatalysis; oxidation

Catalysis by gold nanoparticles is a topic of increasing interest. The aim of this Special Issue was to cover representative works dealing with gold nanoparticle-based catalysts in order to highlight the newest developments and applications in the field.

Gold nanotriangles (Au NTs) were used as catalysts for the selective oxidation of cyclohexane to produce cyclohexanol and cyclohexanone production in [1]. The process is of large industrial and economic importance in the production of adipic acid, a building block for different processes in the pharmaceutical, chemical and food industries, used in the synthesis of nylon- 6,6 polyamide (primary use), but also in the production of polyurethane resins and polyester. Au NTs were prepared following a three-step (seed preparation, growth and shaping) procedure and applied, for the first time, as catalysts for the selective oxidation of cyclohexane to ketone and alcohol (KA) oil (cyclohexanol and cyclohexanone mixture). The Au NTs successfully yielded KA oil (up to 14\%) under mild conditions, namely at $50{ }^{\circ} \mathrm{C}$ temperature, and a "green" oxidant (aqueous tert-butylhydroperoxide), with an alternative energy source (microwave irradiation) as reaction promotor. In contrast, the current industrial process uses a Co homogeneous catalysis, at $150^{\circ} \mathrm{C}$, with $\mathrm{O}_{2}$ as oxidant; yields vary from $4-12 \%$ and selectivities from $80-85 \%$ [2,3]. The catalyst reported in [1] was much more selective $(100 \%$ selectivity was found) and obtained under mild conditions.

Gold nanoparticles smaller than $3 \mathrm{~nm}$ were deposited on different samples of $\mathrm{MnO}_{2}$, with low (commercial $\mathrm{MnO}_{2}$ ) and high (NF, nanoflowers and $\mathrm{NW}$, nanowires $\mathrm{MnO}_{2}$ ) surface area, as reported in [4]. Materials were tested in the base-free oxidation of furfural under mild conditions (air as oxidant, $110^{\circ} \mathrm{C}$ ). High activity was observed for $\mathrm{Au} / \mathrm{MnO}_{2}-\mathrm{NF}$ materials with very high selectivity to furoic acid. X-ray photoelectron spectroscopy (XPS) confirmed the presence of a significant amount of highly active $\mathrm{Au}^{\delta+}$ species on the surface of that samples. Cationic gold seemed to be responsible for the high activity found. Cationic gold species were also found to be fundamental for the oxidation of octanol, with gold nanoparticles supported on a La-Ti mixed oxide [5].

Au catalysts supported on modified montmorillonite were prepared in [6], and tested in methanol steam reforming at $250-500{ }^{\circ} \mathrm{C}$. Among the used catalysts, $\mathrm{Au}-\mathrm{Ti}-\mathrm{Ce} / \mathrm{Na}-\mathrm{ABen}$ (ABen-alkali activated bethonite) exhibited the best catalytic performance with methanol conversion of $72 \%$ and $\mathrm{H}_{2}$ selectivity of $99 \%$ at $350{ }^{\circ} \mathrm{C}$. This could be attributed to the $\mathrm{Au}, \mathrm{Ce}$, and Ti species which form a solid solution and move into the interlayer space of the bentonite leading to a high surface area, large average pore volume, large average pore diameter, and small Au particle size. The synergistic effect of the crosslinking agent, the Ce species, and the Au active sites were responsible for the high activity of that catalyst. 
This special issue also includes a review paper [7] dealing with the principles and applications of tip-enhanced Raman spectroscopy (TERS). The fundamental theory and setup of TERS is presented in detail and also the current advanced reports on TERS, especially for plasmon-driven reactions. This technique has advantages in the field of plasmon-driven surface catalytic reactions. Also, some challenges and the outlook for the future are discussed. The use of Au TERS for plasmon-driven synthesis catalysis and for dissociation reactions is also introduced. This paper provides a deeper understanding of Au TERS for plasmon-driven catalytic reactions.

Another review paper, dealing with the progress in the utilization efficiency and improvement of hot carriers in plasmon-mediated photocatalysis is found in [8]. The effect of plasmon-induced hot carriers (HCs) allows the use of semiconductors with wide band gaps to visible light catalysis, which is a recent interesting research area in environmental protection. The search for an efficient heterostructure photocatalytic process with controllable behaviors of HCs continues. Recently, it has been discovered that the improvement of the utilization of HCs by band-structure engineering can be a promising strategy for the improvement of the catalytic process, and relevant works on the subject have been published. In this paper, authors provide an overview of the recent progress related to optimized methods for designing efficient photocatalysts. The basic mechanism of the heterostructure photocatalytic process is discussed, including the formation of the Schokkty barrier and the process of photocatalysis. Then, the latest studies for improving the utilization efficiency of HCs (including their generation and extraction) are introduced. The applications of such heterostructure photocatalysts, namely in water/air treatments and organic transformations, are briefly illustrated. The remaining challenges and future directions in the field are also discussed.

Finally, the special issue also includes a letter dealing with the enhanced photocatalytic efficiency of $\mathrm{TiO}_{2}$ membrane decorated with $\mathrm{Ag}$ and Au nanoparticles (NPs) used for the catalytic degradation of Rhodamine B (RhB) and Escherichia coli (E. coli) under irradiation of visible light [9]. Ag and Au NPs (2-10 nm size) were deposited on the surface of $\mathrm{TiO}_{2}$ membranes by hydrothermal synthesis and photoreduction methods. It was found that both $\mathrm{Ag}$ - and Au-decorated $\mathrm{TiO}_{2}$ membranes exhibited excellent photocatalytic activity in the visible light region. Nevertheless, the $\mathrm{Ag}-\mathrm{TiO}_{2}$ membrane prepared by photoreduction showed the highest activity, which could be attributed to the local surface plasmon resonance (LSPR) effect of silver.

I must clarify that the first part of this editing work was carried out while I was at Porto University and the more recent part when I moved to Lisbon University, my present address. As guest editor of this special issue, together with Prof. Hiroaki Tada (from Kindai University, Japan), I am thankful to all the authors who contributed and also to the staff members of MDPI for their editorial support. I trust readers will find the papers of this special issue to be helpful and interesting examples of the use of gold nanoparticles in catalytic applications.

Funding: I am thankful to Fundação para a Ciência e a Tecnologia (FCT) for Investigador FCT program (IF/01381/2013/CP1160/CT0007), with financing from the European Social Fund and the Human Potential Operational Program (POCH). This work was supported by Associate Laboratory LSRE-LCM-UID/EQU/50020/2019-funded by national funds through FCT/MCTES (PIDDAC) and also by FCT project UID/QUI/00100/2019.

Conflicts of Interest: I declare no conflict of interest.

\section{References}

1. Matias, I.A.; Ribeiro, A.P.; Oliveira-Silva, R.P.; Prazeres, D.M.; Martins, L.M. Gold Nanotriangles as Selective Catalysts for Cyclohexanol and Cyclohexanone Production. Appl. Sci. 2018, 8, 2655. [CrossRef]

2. Elvers, B. Ullmann's Encyclopedia of Industrial Chemistry, 6th ed.; Ullmann, F., Hawkins, S., Schula, G., Gerhartz, W., Russey, W.E., Elvers, B., Eds.; Wiley-VCH: Weinheim, Germany, 2016; Volume 11, pp. 41-49.

3. Weissermel, K.; Arpe, H.J. Industrial Organic Chemistry, 2nd ed.; Weissermel, K., Arpe, H.J., Eds.; Wiley-VCH: Weinheim, Germany, 1993; ISBN 3-527-26995-9. 
4. Ferraz, C.P.; Da Silva, A.G.M.; Rodrigues, T.S.; Camargo, P.H.C.; Paul, S.; Wojcieszak, R. Furfural Oxidation on Gold Supported on $\mathrm{MnO}_{2}$ : Influence of the Support Structure on the Catalytic Performances. Appl. Sci. 2018, 8, 1246. [CrossRef]

5. Pakrieva, E.; Kolobov, E.; Mamontov, G.; Bogdanchikova, N.; Farias, M.H.; Pascual, L.; Cortés-Corberán, V.; Martinez-Gonzalez, S.; Carabineiro, S.A.; Pestryakov, A. Green Oxidation of n-Octanol on Supported Nanogold Catalysts: Formation of Gold Active Sites under Combined Effect of Gold Content, Additive Nature and Redox Pretreatment. ChemCatChem 2019, 11, 1615. [CrossRef]

6. Zhang, R.; Huang, C.; Zong, L.; Lu, K.; Wang, X.; Cai, J. Hydrogen Production from Methanol Steam Reforming over $\mathrm{TiO}_{2}$ and $\mathrm{CeO}_{2}$ Pillared Clay Supported Au Catalysts. Appl. Sci. 2018, 8, 176. [CrossRef]

7. Wang, J.; Qiao, W.; Mu, X. Au Tip-Enhanced Raman Spectroscopy for Catalysis. Appl. Sci. 2018, 8, 2026. [CrossRef]

8. Zhang, T.; Wang, S.J.; Zhang, X.Y.; Su, D.; Yang, Y.; Wu, J.Y.; Xu, Y.Y.; Zhao, N. Progress in the Utilization Efficiency Improvement of Hot Carriers in Plasmon-Mediated Heterostructure Photocatalysis. Appl. Sci. 2019, 9, 2093. [CrossRef]

9. Gao, Y.; Zhang, W.; Liu, P. Enhanced Photocatalytic Efficiency of $\mathrm{TiO}_{2}$ Membrane Decorated with $\mathrm{Ag}$ and $\mathrm{Au}$ Nanoparticles. Appl. Sci. 2018, 8, 945. [CrossRef]

(C) 2019 by the author. Licensee MDPI, Basel, Switzerland. This article is an open access article distributed under the terms and conditions of the Creative Commons Attribution (CC BY) license (http://creativecommons.org/licenses/by/4.0/). 